\title{
IDENTIFICAÇÃO E UTILIZAÇÃO DE Trichoderma spp. ARMAZENADOS E NATIVOS NO BIOCONTROLE DE Sclerotinia sclerotiorum ${ }^{1}$
}

\author{
GERARDA BEATRIZ PINTO DA SILVA ${ }^{2 *}$, LEISE INÊS HECKLER ${ }^{3}$, RICARDO FELICIANO DOS SANTOS $^{4}$, \\ MIRIA ROSA DURIGON ${ }^{5}$, ELENA BLUME ${ }^{3}$
}

\begin{abstract}
RESUMO - O fungo Sclerotinia sclerotiorum é responsável por perdas significativas na produção de alface. Por se tratar de um fungo habitante do solo seu manejo é dificultado, sendo uma alternativa o uso do controle biológico utilizando espécies do gênero Trichoderma. Dessa forma, os objetivos deste trabalho foram identificar as espécies Trichoderma spp. nativas presentes em solo com (CP) e sem mofo-branco (SP), avaliar a velocidade de crescimento e o antagonismo in vitro dos isolados de Trichoderma spp. à S. sclerotiorum e verificar o potencial de biocontrole proporcionado por Trichoderma spp. microbiolizado em sementes de alface, cultivadas em substrato infestado com S. sclerotiorum. Foram utilizados isolados de Trichoderma spp. oriundos de áreas com e sem histórico de mofo-branco ou armazenados em água. Nos ensaios in vitro foram avaliados a taxa de crescimento micelial e a esporulação dos isolados de Trichoderma spp. e controle de Trichoderma spp. versus S. sclerotiorum. Para o ensaio in vivo sementes de alface foram microbiolizadas com Trichoderma spp. e o substrato infestado com S. sclerotiorum. Os isolados nativos de Trichoderma identificados pertencem às espécies T. koningiopsis e T. asperellum. Os isolados CP apresentaram maior taxa de crescimento micelial quando comparado aos SP e aos armazenados, enquanto que os isolados armazenados apresentaram melhores respostas na confrontação direta. A aplicação de Trichoderma spp. promoveu o crescimento de plântulas de alface mais vigorosas quando comparadas à testemunha, assim como um bom desenvolvimento das plântulas na presença do patógeno.
\end{abstract}

Palavras-chave: Mofo-branco. Controle biológico. Lactuca sativa L.

\section{IDENTIFICATION AND UTILIZATION OF Trichoderma spp. STORED AND NATIVE IN Sclerotinia sclerotiorum BIOCONTROL}

\begin{abstract}
The fungus Sclerotinia sclerotiorum, handles significant losses in lettuce production. Being a soil borne fungus, its management is difficult, and an alternative is the use of biological control using species of the Trichoderma genus. Thus, the objectives of this study were to identify native species of Trichoderma spp. presents in the soil with (CP) and without white mold (SP), evaluate the growth rate and in vitro antagonism of Trichoderma spp. against S. sclerotiorum and to verify the biocontrol potential of Trichoderma spp. microbiolized lettuce seeds, growing in substrate infested with S. sclerotiorum. Trichoderma spp. isolates were obtained from areas with and without history of white mold or stored in water. Mycelial growth rate and sporulation of the Trichoderma spp. isolates and control of Trichoderma spp. versus S. sclerotiorum in the in vitro essays. For thein vivo essay, lettuce seeds were microbiolized with Trichoderma spp. and the substrate was infested with $S$. sclerotiorum. The native isolates of Trichoderma identified belong to T. koningiopsis and T. asperellum species. The $\mathrm{CP}$ isolates had higher mycelial growth rates when compared to the SP isolates and stored while the stored isolates showed better responses in confrontation. The application of Trichoderma spp. promoted higher seedlings quality compared to control, as well as good seedlings development in the presence of the pathogen.
\end{abstract}

Keywords: White mold. Biological control. Lactuca sativa L.

\footnotetext{
*Autor para correspondência

${ }^{1}$ Recebido para publicação em 20/04/2014; aceito em 06/06/2015

Artigo extraído da Dissertação de Mestrado do primeiro autor.

${ }^{2}$ Departamento de Fitossanidade, Universidade Federal do Rio Grande do Sul - UFRGS, Faculdade de Agronomia, Av. Bento Gonçalves, 7712, 91540-000, Porto Alegre(RS), Brasil; gerardabeatriz@gmail.com.

${ }^{3}$ Departamento de Defesa Fitossanitária, Universidade Federal de Santa Maria - UFSM, Av. Roraima, 1000, 97105-900, Santa Maria(RS), Brasil; leiseheckler@gmail.com, elenablu@gmail.com.

${ }^{4}$ Departamento de Fitopatologia, Universidade de São Paulo - USP, Escola Superior de Agricultura "Luiz de Queiroz" - ESALQ, Av. Pádua Dias, 11, 13418-900, Piracicaba(SP), Brasil; ricardofelicianodossantos@gmail.com.

${ }^{5}$ Faculdade de Agronomia e Medicina Veterinária, FAMV, Universidade de Passo Fundo - UPF, BR 285, São José, 99052-900, Passo Fundo(RS), Brasil; midurigon@yahoo.com.br.
} 


\section{INTRODUÇ̃̃̃}

Sclerotinia sclerotiorum (Lib.) de Bary é um fitopatógeno habitante do solo que infecta importantes culturas agrícolas no Brasil como, por exemplos, alface, soja, feijão, canola, girassol etc. A rotação de culturas não é um método efetivo de controle, visto que o patógeno possui uma gama de hospedeiros, que aliados à persistência de suas estruturas de resistência no solo dificultam o manejo (KIN et al., 2011). Sabe-se que a alface é a hortaliça folhosa mais consumida pela população brasileira, sendo produzida em todos os estados da federação (SALA; COSTA, 2012). Entretanto, apresenta alta suscetibilidade a diversas doenças fitopatogênicas, em especial a $S$. sclerotiorum, causadora de uma enfermidade popularmente conhecida como mofo-branco (LOPES et al., 2012), devido a presença de um micélio branco de aspecto cotonoso nas plantas infectadas. Em condições de alta umidade e temperaturas amenas os danos causados por S. sclerotiorum podem chegar a mais de 50\% (CLARKSON et al., 2014), principalmente em viveiros de mudas, onde ocasionam o $d a$ mping off ou tombamento de plântulas.

Devido a falta de cultivares resistentes para muitos hospedeiros, entres eles a alface (CLARKSON et al., 2014) e aos riscos inerentes ao uso de agrotóxicos no consumo dessa hortaliça, muitos produtores têm se interessado pela utilização do controle biológico. Atualmente o gênero Trichoder$m a$ é o mais estudado e utilizado no controle biológico de patógenos habitantes do solo. Vários mecanismos de ação, como produção de antibióticos voláteis e não-voláteis, competição por espaço e nutrientes, atividade enzimática hidrolítica e parasitismo (BRITO et al., 2014; ABDULLAH et al., 2008) atuam no controle. Estudos recentes apontam que mais de 1100 estirpes de Trichoderma spp., obtidas a partir de 75 espécies, são capazes de desempenhar atividade microparasítica contra os patógenos Alternaria alternata, Botrytis cinerea e S. sclerotiorum (DRUZHININA et al., 2011).

A eficácia do uso de Trichoderma spp. como agente de biocontrole requer um entendimento aperfeiçoado da ecologia da rizosfera, uma vez que os respectivos fungos são ubíquos e sua colonização é seriamente afetada pela presença de substratos orgânicos no solo (BRITO et al., 2010; ETHUR, 2006). Apesar do uso de Trichoderma spp. no controle de doenças existem poucas informações sobre a sobrevivência e a manutenção de sua atividade em condições de armazenamento. Em estudos realizados in vitro Garcia-Núñez et al. (2012) relataram que isolados de Trichoderma spp. nativos são mais agressivos do que os armazenados. Semelhantemente, testes in vivo demostraram que $T$. harzianum nativos foram mais efetivos no controle de S. sclerotiorum do que isolados comerciais armazenados, já que não somente inibiram o crescimento de $S$. sclerotiorum, o que também ocorreu nos comerciais, mas também foram capazes de parasitá-lo através da penetração e colonização das hifas (ABDULLAH et al., 2008).

O presente estudo teve por objetivo identificar espécies de Trichoderma spp. nativas presentes no solo de áreas com e sem histórico de mofo-branco, avaliar o antagonismo in vitro de espécies nativas e de isolados armazenados sobre $S$. sclerotiorum e avaliar o desenvolvimento de plântulas de alface microbiolizadas com Trichoderma spp. e semeadas em substrato previamente inoculado com $S$. sclerotiorum.

\section{MATERIAL E MÉTODOS}

Os ensaios foram conduzidos na Universidade Federal de Santa Maria - UFSM (RS) no período de agosto a outubro de 2012.

\section{Ensaios in vitro}

Foram realizadas oito coletas de solo em quatro áreas comerciais de Santa Maria (RS), ou seja, duas coletas por área. Quatro amostras de solo foram coletadas em área onde foi constatada a presença de mofo-branco em alface e quatro em áreas de primeiro cultivo de alface, que antes do plantio estavam em pousio e não apresentavam histórico da doença. Raízes de alface com solo aderido foram retiradas com o auxílio de uma pá de corte e, posteriormente, separadas deste. $\mathrm{O}$ solo foi acondicionado em sacos plásticos e levado ao laboratório, permanecendo sob refrigeração a $4{ }^{\circ} \mathrm{C}$ até ser usado nos ensaios de isolamento de Trichoderma spp.

Foram utilizados 12 isolados de Trichoderma spp., dos quais quatro estavam armazenados na micoteca da UFSM e o restante obtidos das amostras de solo coletadas. Os quatro isolados armazenados foram UFSMT17 (Trichoderma aureoviride Rifai), UFSMT15.1 (Trichoderma koningiopsis Samuels, Suárez \& Evans), ETSR20 (T. harzianum) e TC1.15 (Trichoderma asperellum Samuels, Lieckf \& Nirenberg). Para a obtenção dos oito isolados nativos de Trichoderma spp. foi usado o método de iscas (GHINI; KIMATI, 1989), sendo selecionado um isolado de cada área amostrada.

$\mathrm{O}$ isolado de $S$. sclerotiorum foi obtido a partir de escleródio presente em planta de alface infectada com mofo-branco e sua assepsia realizada com álcool $70 \%$ por um minuto, solução de hipoclorito de sódio a $0,5 \%$ por um minuto e água destilada e esterilizada. Para o isolamento, o escleródio foi transferido para placa de Petri contendo meio de cultura batata-dextrose-ágar (BDA) acrescido de 0,03 g. $\mathrm{L}^{-1}$ de sulfato de estreptomicina e incubado a $25^{\circ} \mathrm{C}$, no escuro. Após sete dias foi verificado o crescimento característico do micélio branco do fungo e formação de escleródios. A partir dessa placa foram feitas repicagens do patógeno para serem usadas nos ensaios.

Os 12 isolados de Trichoderma spp. e um de 
S. sclerotiorum foram avaliados quanto a taxa de crescimento micelial de ambos os fungos e a esporulação apenas de Trichoderma spp., em meio de cultura BDA. As medições foram realizadas durante dois dias, mensuradas com o auxílio de um paquímetro digital em dois sentidos perpendiculares marcados no fundo de cada placa para que as medidas sempre fossem no mesmo sentido. Foram utilizadas as médias de duas medidas para calcular a taxa de crescimento micelial em $\mathrm{mm} \cdot \mathrm{h}^{-1}$, aplicando-se a fórmula adaptada de Lilly e Barnett (1951), qual seja: C2 é o crescimento após 48 horas; $\mathrm{C} 1$ o crescimento após 24 horas; $\mathrm{T} 2=48 \mathrm{~h}$; e $\mathrm{T} 1=24 \mathrm{~h}$.

$$
\text { Taxa de crescimento }=\frac{(\mathrm{C} 2-\mathrm{C} 1)}{(\mathrm{T} 2-\mathrm{T} 1)}
$$

Para avaliar o antagonismo de Trichoderma spp. contra o patógeno $S$. sclerotiorum os isolados foram repicados e utilizados aos cinco dias de idade. Seguiu-se a metodologia descrita por Ethur (2006), em que um disco de meio de cultura BDA (10 mm ø) contendo micélio do patógeno foi colocado a $0,5 \mathrm{~cm}$ da borda das placas de Petri e estas incubadas por 48 h a $20 \pm 2{ }^{\circ} \mathrm{C}$, com fotoperíodo de $12 \mathrm{~h}$. Decorrido esse período um novo disco de meio de cultura (10 mm ø) contendo micélio de Trichoderma spp. foi depositado na extremidade oposta da placa. As placas foram incubadas em câmara BOD com fotoperíodo de $12 \mathrm{~h}$, por sete dias.

As avaliações do confronto direto seguiram duas escalas, uma proposta por Bell et al. (1982) com notas de antagonismo variando de 1 a 5, baseadas em uma análise visual, em que na nota $1 \mathrm{o}$ antagonista cresce e ocupa toda a placa e na nota 5 o patógeno cresce e ocupa toda a placa, e a outra pela escala adaptada de Rodrigues (2010), baseada em um gabarito que é posicionado sob as placas (Figura 1), cujas notas variam de 1 a 7 , na qual 1 o antagonista cresce e ocupa toda a placa e 7 o patógeno cresce e ocupa toda a placa. O uso da escala de Rodrigues visa uma maior confiabilidade na obtenção das notas, além de uma maior amplitude na escala de valores, já que se baseia em um gabarito fixo. Para a avaliação da porcentagem de inibição das colônias de S. sclerotiorum foram medidas as colônias do patógeno e estimada a porcentagem com base no diâmetro total da placa.

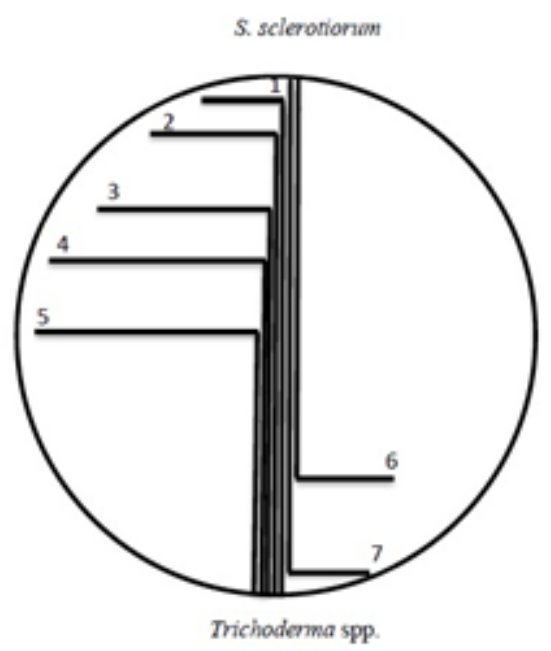

Figura 1. Gabarito da escala adaptada de Rodrigues (2010) com notas variando de 1 a 7 . A nota 1 significa a máxima eficiência em colonização de Trichoderma spp. e a nota 7 a completa colonização da placa com Sclerotinia sclerotiorum. Santa Maria (RS), 2012.

\section{Identificação das espécies de Trichoderma spp.}

Os oito isolados de Trichoderma spp. nativos foram divididos em dois grupos CP (oriundo de áreas com histórico de mofo-branco) e SP (oriundo de áreas sem histórico de mofo-branco), os quais foram encaminhados ao Instituto Biológico de São Paulo para identificação molecular em nível de espécie. Para a identificação foi realizado o sequenciamento, a partir da extração do DNA, amplificação da região ITS e do gene codificador do fator de elongação $1-\propto$. As sequências obtidas foram comparadas com as depositadas no GenBank, utilizando-se os oligonucleotídeos iniciadores ITS1 e ITS4.

\section{Preparo de Trichoderma spp.}

Foi realizado seguindo a metodologia descrita por Ethur (2006), em que $200 \mathrm{~g}$ de grãos de arroz seco foram previamente umedecidos com água destilada e depositados em frascos de Erlenmeyer de 350 $\mathrm{ml}$ e autoclavados por $40 \mathrm{~min}$ duas vezes a $120^{\circ} \mathrm{C}$ e 1 atm. Em cada frasco foram acrescentados cinco discos $(10 \mathrm{~mm})$ contendo micélio dos isolados de Trichoderma spp. separadamente, os quais permaneceram em câmara climatizada a $22^{\circ} \mathrm{C}$ com fotoperíodo de $12 \mathrm{~h}$ por 15 dias para a colonização completa dos grãos de arroz. Para serem utilizados nos ensaios os grãos já colonizados foram secos na estufa por 48 $\mathrm{h}$ em temperatura constante de $37{ }^{\circ} \mathrm{C}$. Em seguida 
foram triturados em liquidificador até a obtenção de um pó e armazenados sob refrigeração a $4{ }^{\circ} \mathrm{C}$. Para estimar a concentração de esporos de Trichoderma spp. presentes nos pós utilizou-se a câmara de Neubauer com auxílio de microscópio.

\section{Ensaio in vivo}

Foram utilizados 12 isolados de Trichoderma spp., dos quais quatro encontravam-se armazenados na micoteca da UFSM e oito nativos obtidos em ensaios anteriores. O delineamento experimental utilizado foi inteiramente casualizado no esquema fatorial $12 \times 2$ (isolados de Trichoderma spp. x infestação ou não do substrato com S. sclerotiorum) mais uma testemunha absoluta. Para a avaliação do potencial de biocontrole de $S$. sclerotiorum em plântulas de alface foi realizado um ensaio utilizando-se bandejas de isopor com 200 células cada e substrato comercial Mec Plant ${ }^{\circledR}$. As bandejas permaneceram em câmara climatizada com temperatura de $25^{\circ} \mathrm{C}$ e fotoperíodo de $12 \mathrm{~h}$, sendo irrigadas de maneira uniforme diariamente.

Sementes de alface cv. Regina foram microbiolizadas $24 \mathrm{~h}$ antes da semeadura, com a formulação de Trichoderma spp. em pó com concentração de aproximadamente $2 \times 10^{6}$ esporos.g ${ }^{-1}$, semeando-se apenas uma semente por célula para não superestimar a concentração do antagonista. Devido a falta de padronização para aplicações de Trichoderma spp. em formulações em pó, principalmente em sementes de alface, adotou-se a proporção de $1 \mathrm{~g}$ de pó para cada $1 \mathrm{~g}$ de sementes. Ambos foram pesados separadamente e colocados juntos em placas de Petri, as quais foram seladas com filme plástico e agitadas por 2 min a fim de uma melhor uniformização de cobertura das sementes, repetindo-se a agitação 3 vezes. As placas contendo as sementes microbiolizadas permaneceram em temperatura ambiente $\left(25^{\circ} \mathrm{C}\right)$ por $24 \mathrm{~h}$ até serem utilizadas.

As bandejas utilizadas continham substrato previamente infestado por $48 \mathrm{~h}$ com uma suspensão de micélio do patógeno, na proporção de uma placa de Petri contendo S. sclerotiorum com cinco dias de idade, para cada bandeja. Foram utilizadas quatro repetições com 25 sementes cada, totalizando 100 sementes por tratamento.

Para determinar o Índice de Velocidade de Emergência (IVE) foram realizadas contagens diárias do número de sementes emergidas e seu valor calculado conforme a fórmula proposta por Brasil (2009). Quando a emergência se estabilizou fora determinada a porcentagem de emergência e, ao final do experimento, determinada a porcentagem de plantas so- breviventes. As avaliações finais foram realizadas 21 dias após a semeadura e as variáveis analisadas foram comprimento da parte aérea e sistema radicular, matéria seca da parte aérea e do sistema radicular e matéria seca total.

\section{Análise estatística}

Os dados obtidos nos ensaios apresentaram distribuição normal, foram submetidos à análise de variância para verificação da significância e realizada a comparação de médias utilizando-se o teste de Scott-Knott a 5\% de probabilidade de erro. Para essas análises foi utilizado o software estatístico SISVAR 5.3 (FERREIRA, 2011).

\section{RESULTADOS E DISCUSSÃO}

\section{Identificação dos isolados de Trichoderma spp.}

A partir do sequenciamento do DNA dos isolados foi possível realizar sua identificação em nível de espécie, quais sejam: Trichoderma koningiopsis Samuels; Suárez \& Evans para SP13 e SP23; Trichoderma asperellum Samuels; e Lieckf \& Nirenberg para CP11, CP12, CP21, CP22, SP14 e SP24. As espécies identificadas são conhecidas e utilizadas no controle biológico de fitopatógenos habitantes do solo, inclusive para o controle de S. sclerotiorum (LOPES et al., 2012; RODRIGUES, 2010). HoyosCarvajal et al. (2009), estudando a biodiversidade de 183 isolados de Trichoderma spp. em sete países da América do Sul, incluindo o Brasil, observaram que T. asperellum foi a espécie encontrada em maior frequência, com 60 isolados, seguida de T. harzianum com 49.

As espécies encontradas neste trabalho estão de acordo com Lopes et al. (2012), os quais obtiveram 21 isolados oriundos do Cerrado brasileiro, sendo nove $T$. asperellum (42,86\%), sete T. harzianum (33,33\%), três Trichoderma tomentosum Bissett (14,29\%), um T. koningiopsis (4,76\%) e um Trichoderma erinaceum (Bissett, Kubicek \& Szakacs) (4,76\%). A espécie T. asperellum pode ser considerada como uma das mais abundantes em solos brasileiros.

\section{Ensaios in vitro}

De modo geral, os isolados do antagonista tiveram significativamente maior taxa de crescimento micelial do que o fitopatógeno, com exceção do isolado TC1.15 (Figura 2). 


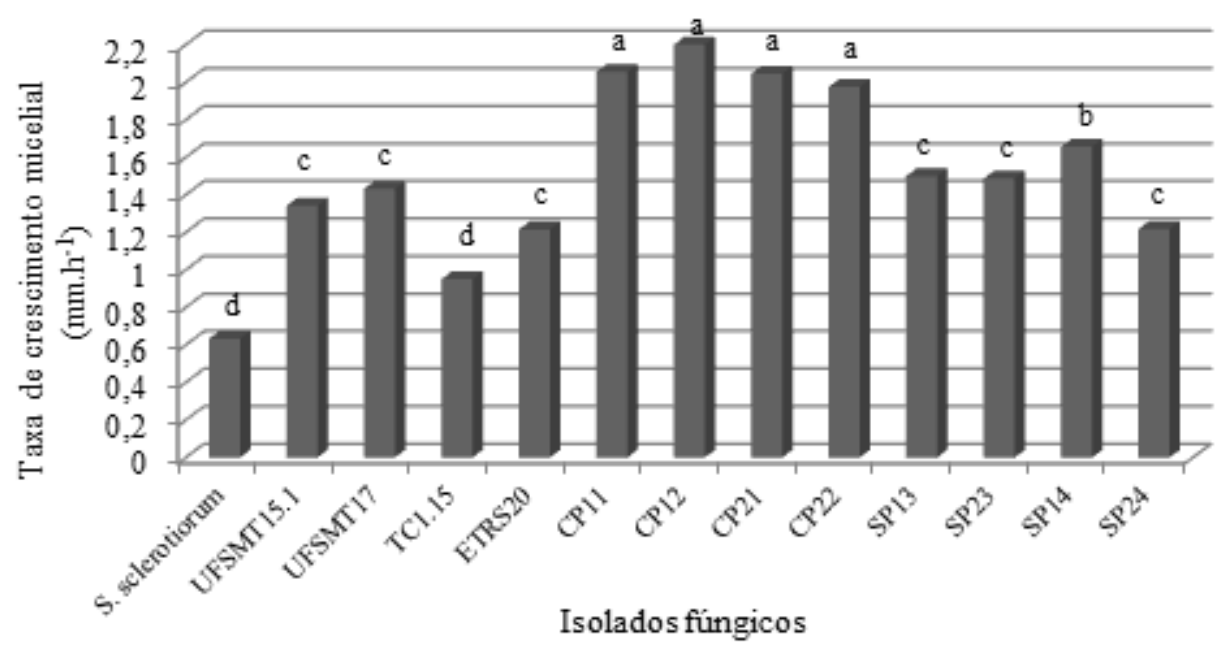

Figura 2. Taxa de crescimento micelial $\left(\mathrm{mm} \cdot \mathrm{h}^{-1}\right)$ de Sclerotinia sclerotiorum e de Trichoderma spp. Barras com a mesma letra não diferem estatisticamente entre si pelo teste de Scott-Knott a 5\% de probabilidade. Santa Maria (RS), 2012.

Os isolados pertencentes ao grupo CP mostraram-se estatisticamente superiores aos demais, sugerindo que a convivência com o patógeno em campo acelera a taxa de crescimento micelial de Trichoderma spp. in vitro e que podem ser bons competidores por espaço e pouco exigentes quanto a nutrientes específicos, visto que foram cultivados meio de cultura BDA. Brito et al. (2010) relataram que isolados armazenados apresentaram crescimento inferior quando comparados aos isolados obtidos de compostos orgânicos, corroborando com os dados deste trabalho, no qual os isolados da micoteca apresentaram as menores taxas de crescimento, recomendando que ocorre decréscimo na viabilidade devido ao armazenamento prolongado.

Os resultados apresentados pelos isolados do grupo SP sugerem que na ausência da doença a taxa de crescimento de Trichoderma spp. é estatisticamente menor do que onde há frequente pressão exercida pelo mofo-branco. Os isolados de Trichoderma spp. apresentaram taxas de crescimento variando de aproximadamente 2,2 a $0,9 \mathrm{~mm} \cdot \mathrm{h}^{-1}$ e $0,6 \mathrm{~mm} \cdot \mathrm{h}^{-1}$ para o patógeno, superando os valores encontrados por Barakat et al. (2006), que ao utilizarem isolados de diferentes origens obtiveram taxas variando de 1,125 a $0,5 \mathrm{~mm} \cdot \mathrm{h}^{-1}$ para Trichoderma spp. e $0,17 \mathrm{~mm} \cdot \mathrm{h}^{-1}$ para Sclerotium rolfsii Sacc.

No teste de confrontação direta (Tabela 1) observou-se que a escala proposta por Rodrigues (2010) foi mais precisa do que a de Bell (1982), uma vez que apresentou um coeficiente de variação menor. Por se tratar de uma escala de avaliação mais objetiva a escala de Rodrigues (2010) presumivelmente permite resultados mais acurados.

Tabela 1. Classificação dos isolados de Trichoderma spp. quanto ao antagonismo a Sclerotinia sclerotiorum segundo as escalas de Bell (1982) e Rodrigues (2010) e porcentagem de inibição de crescimento (\%) de Sclerotinia sclerotiorum. Santa Maria (RS), 2012.

\begin{tabular}{lccc}
\hline Trichoderma spp. & Bell (1982) & Rodrigues (2010) & Inibição de S. sclerotiorum (\%) \\
\hline UFSMT15.1 & $2,0 \mathrm{~b}^{1}$ & $3,2 \mathrm{~b}$ & $63,03 \mathrm{~b}$ \\
UFSMT17 & $2,2 \mathrm{~b}$ & $2,2 \mathrm{~b}$ & $49,12 \mathrm{c}$ \\
TC1.15 & $5,0 \mathrm{a}$ & $5,0 \mathrm{a}$ & $47,76 \mathrm{c}$ \\
ETSR20 & $2,5 \mathrm{~b}$ & $4,6 \mathrm{a}$ & $45,88 \mathrm{c}$ \\
CP11 & $4,6 \mathrm{a}$ & $4,8 \mathrm{a}$ & $37,70 \mathrm{c}$ \\
CP12 & $4,2 \mathrm{a}$ & $4,2 \mathrm{a}$ & $42,63 \mathrm{c}$ \\
CP21 & $2,0 \mathrm{~b}$ & $2,6 \mathrm{~b}$ & $72,68 \mathrm{a}$ \\
CP22 & $3,6 \mathrm{~b}$ & $4,2 \mathrm{a}$ & $55,99 \mathrm{~b}$ \\
SP13 & $4,6 \mathrm{a}$ & $5,2 \mathrm{a}$ & $47,76 \mathrm{c}$ \\
SP23 & $4,4 \mathrm{a}$ & $5,8 \mathrm{a}$ & $43,26 \mathrm{c}$ \\
SP14 & $4,4 \mathrm{a}$ & $5,8 \mathrm{a}$ & $48,62 \mathrm{c}$ \\
SP24 & $4,4 \mathrm{a}$ & $5,8 \mathrm{a}$ & $48,62 \mathrm{c}$ \\
CV $(\%)$ & 26,66 & 22,90 & 17,78 \\
\hline
\end{tabular}

${ }^{1}$ Valores seguidos pela mesma letra, na coluna, não diferem estatisticamente, segundo o teste de Scott-Knott a $5 \%$ de probabilidade; ${ }^{2} \mathrm{CP}$ : isolados provenientes de áreas com histórico de mofo-branco; ${ }^{3} \mathrm{SP}$ : isolados provenientes de áreas sem histórico de mofo-branco. 
A redução do crescimento micelial de $S$. sclerotiorum apresentou diferença significativa para os isolados testados, sendo CP21 o melhor, reduzindo $73 \%$ do crescimento micelial do patógeno, seguido de UFSMT15.1 e CP22, com 63 e 56\%, respectivamente. Os resultados desse ensaio variaram de 38 a $73 \%$, corroborando com os dados obtidos por Ávila et al. (2005) que conseguiram porcentagem de inibição variando de 30 a 70\%. Estudos recentes demonstram que espécies de Trichoderma spp. atuam distintamente na inibição de $S$. sclerotiorum (QUALHATO et al., 2013). Segundo Lopes et al. (2012), T. asperellum 11/11 e T. harzianum ALL-42 apresentaram mais de $50 \%$ de inibição, enquanto que T. tementosum 36/02, T. asperellum 400/01 e $T$. tementosum 476-02 menos de 10\%. Barakat et al. (2006), utilizando 69 isolados de Trichoderma spp. obtidos de diferentes regiões da Palestina, obtiveram 47 isolados com significativa redução no crescimento micelial de $S$. sclerotiorum, variando de 20,8 a $66,8 \%$, sendo os mais promissores pertencentes às espécies T. harzianum, T. pseudokoningii e T. lactea.

Para a confrontação direta, os melhores resultados foram evidenciados pelos isolados CP21 e os armazenados, exceto TC1.15, uma vez que apresentaram nota igual ou inferior a 4, na escala de Bell (1982), enquanto os menos promissores foram os isolados do grupo SP, considerados pouco eficientes. Apesar dos isolados CP terem exibido a maior taxa de crescimento micelial apenas CP21 mostrou destaque na confrontação direta, sugerindo o envolvimento de mais de um mecanismo de ação, como liberação de metabólitos ou parasitismo. Vale ressaltar que o isolado TC1.15 teve lenta taxa de crescimento micelial, igualando-se ao patógeno, e baixa concentração de esporos. $\mathrm{mL}^{-1}$, sugerindo que o armazenamento prolongado foi mais prejudicial do que para os demais.

O melhor desempenho na confrontação direta foi apresentado por UFSMT15.1, UFSMT17, ETSR20 e CP21, já que, segundo Ethur (2006), aqueles que apresentarem notas variando de 2 a 2,5 podem ser classificados como eficientes. Louzada et al. (2009) consideram que um isolado é antagônico ou eficiente, quando sua nota é menor ou igual a 3,0. Esse autor, trabalhando com amostras de solo com diferentes cultivos, obteve 230 isolados de Trichoderma spp., dos quais 111 apresentaram notas menores do que 3 contra S. sclerotiorum, 50 contra Fusarium solani f. sp. phaseoli (Burkholder) Snyder \& Hansen e apenas 24 isolados contra os dois patógenos, ou seja, $10 \%$ do total. A variação entre as notas desse ensaio (em que aproximadamente $42 \%$ dos isolados apresentaram eficiência antagônica) ocorreu porque o nível de controle varia dependendo da adaptação às condições bióticas e abióticas específicas, as quais os isolados são submetidos dentro e entre as espécies do gênero Trichoderma (DENNIS; WEBSTER, 1971).

Dados de ensaios in vitro mostram que isolados de T. harzianum obtidos da rizosfera de plantas sintomáticas têm capacidade não apenas para inibir o desenvolvimento de patógenos através de metabólitos não voláteis, como também de parasitar, penetrar e colonizar as hifas de $S$. sclerotiorum (ABDULLAH et al., 2008). Outrossim, Louzada et al. (2009) ressaltam que não há relatos na literatura sobre a perda da diversidade de Trichoderma spp. causada pelo uso agrícola contínuo.

\section{Ensaios in vivo}

Fora constatado que a presença de S. sclerotiorum no substrato diminui estatisticamente a porcentagem de germinação de sementes de alface, porém a utilização de Trichoderma spp. associado ao patógeno reduz esse efeito, excetuando-se os isolados UFSMT15.1, CP12, CP21 e SP13 (Tabela 2). A aplicação direta de Trichoderma spp. permite o aumento significativo na porcentagem e precocidade de germinação em sementes de tomate, porém quando armazenados por pelo menos dois meses alguns isolados podem promover decréscimo no stand final das plantas (TSAHOURIDOU; THANASSOULOPOULOS, 2002). Diante disso, na presença apenas do biocontrolador, alguns isolados, os armazenados UFSMT15.1, TC1.15, ETSR20 e os nativos CP21 e SP13, manifestaram-se negativamente, diminuindo a porcentagem de germinação de sementes. Um dos problemas ao tratar sementes com agentes de biocontrole é que estes eventualmente afetam negativamente a germinação (LUCON, 2009), já que podem utilizar a semente com substrato, colonizando-a.

Diferente dos resultados de germinação, a porcentagem de sobrevivência não diferiu entre a testemunha absoluta e a infestada apenas com $S$. sclerotiorum. Os isolados UFSMT17, CP11, CP22, SP23 e SP24 superaram a testemunha absoluta, promovendo ganhos de sobrevivência. TC1.15, no entanto, atuou negativamente na ausência do patógeno, já que foi estatisticamente maior na presença do mesmo. Dos isolados aplicados $75 \%$ apresentaram capacidade de aumentar a sobrevivência das plântulas na presença do patógeno.

Além disso, cerca de $51 \%$ das plântulas testemunha contendo apenas o patógeno sobreviveram 21 dias após a semeadura, comparado com $82 \%$ quando se utilizou o tratamento com $T$. harzianum, obtendo plântulas mais saudáveis e vigorosas (INBAR et al., 1996). Esses resultados confirmam os de Abdullah et al. (2008), que aplicando T. harzianum nativo em plântulas de tomate obtiveram mais de $80 \%$ no controle de $S$. sclerotiorum. 
Tabela 2. Emergência (\%), plântulas sobreviventes (\%) e Índice de Velocidade de Emergência - IVE para plântulas de alface cv. Regina oriundas de sementes tratadas com Trichoderma spp. de diferentes origens, na ausência e presença de S. sclerotiorum. Santa Maria (RS), 2012.

\begin{tabular}{|c|c|c|c|c|c|c|}
\hline & \multicolumn{2}{|c|}{ Germinação (\%) } & \multicolumn{2}{|c|}{ Sobreviventes (\%) } & \multicolumn{2}{|c|}{ IVE } \\
\hline $\begin{array}{c}\text { Trichoderma } \\
\text { spp. }\end{array}$ & Controle & Infestado $^{2}$ & Controle & Infestado & Controle & Infestado \\
\hline Testemunha & $73 \mathrm{aA}^{1}$ & $53 \mathrm{bB}$ & $50 \mathrm{bA}$ & $52 \mathrm{bA}$ & $1,44 \mathrm{aA}$ & $0,80 \mathrm{bB}$ \\
\hline UFSMT15.1 & $51 \mathrm{bA}$ & $53 \mathrm{bA}$ & $39 \mathrm{bA}$ & $47 \mathrm{bA}$ & $0,81 \mathrm{bA}$ & $0,99 \mathrm{bA}$ \\
\hline UFSMT17 & $74 \mathrm{aA}$ & $77 \mathrm{aA}$ & $69 \mathrm{aA}$ & $71 \mathrm{aA}$ & $1,50 \mathrm{aA}$ & $1,82 \mathrm{aA}$ \\
\hline $\mathrm{TC} 1.15$ & $42 \mathrm{bB}$ & $66 \mathrm{aA}$ & $36 \mathrm{bB}$ & $56 \mathrm{aA}$ & $0,80 \mathrm{bA}$ & $1,16 \mathrm{bA}$ \\
\hline CP12 & $76 \mathrm{aA}$ & $41 \mathrm{bB}$ & $54 \mathrm{bA}$ & $40 \mathrm{bA}$ & $1,74 \mathrm{aA}$ & $1,44 \mathrm{aA}$ \\
\hline CP21 & $62 \mathrm{bA}$ & $47 \mathrm{bA}$ & $56 \mathrm{bA}$ & $40 \mathrm{bA}$ & $1,43 \mathrm{aA}$ & $0,82 \mathrm{bA}$ \\
\hline CP22 & $70 \mathrm{aA}$ & $70 \mathrm{aA}$ & $62 \mathrm{aA}$ & $63 \mathrm{aA}$ & $2,02 \mathrm{aA}$ & $1,03 \mathrm{bB}$ \\
\hline SP $13^{3}$ & $62 \mathrm{bA}$ & $58 \mathrm{bA}$ & $51 \mathrm{bA}$ & $56 \mathrm{aA}$ & $1,75 \mathrm{aA}$ & $1,01 \mathrm{bB}$ \\
\hline SP23 & $78 \mathrm{aA}$ & $65 \mathrm{aA}$ & $67 \mathrm{aA}$ & $60 \mathrm{aA}$ & $2,26 \mathrm{aA}$ & $1,51 \mathrm{aB}$ \\
\hline
\end{tabular}

${ }^{1}$ Médias seguidas pela mesma letra minúscula na coluna e maiúscula na linha não diferem estatisticamente, segundo o teste de Scott-Knott $(\mathrm{P} \leq 0,05)$; ${ }^{2}$ Infestado: substrato infestado com $S$. sclerotiorum ${ }^{2} \mathrm{CP}$ : isolados proveniente de áreas com histórico de mofo-branco; ${ }^{3} \mathrm{SP}$ : isolados proveniente de áreas sem histórico de mofo-branco.

Os resultados do IVE (Tabela 2) confirmam que a presença do patógeno é prejudicial ao desenvolvimento inicial de mudas de alface, visto que as testemunhas com e sem inoculação do patógeno diferiram estatisticamente entre si, bem como CP22, SP13 e SP23, que também foram significativamente menores quando comparados aos mesmos tratamentos na ausência do patógeno.

Com exceção dos isolados UFSMT15.1 e $\mathrm{TC} 1.15$, os quais foram significativamente menores do que a testemunha absoluta para a variável IVE, os demais apresentaram capacidade de promover ganhos na velocidade de germinação. Sementes de tomate cv. Jubilee tratadas com T22 (T. harzianum) também tiveram aumento na velocidade de germinação (MASTOURI et al., 2010).

O tratamento com Trichoderma spp. promoveu ganhos de comprimento da parte aérea nas plântulas de alface de até $1,16 \mathrm{~cm}$ ou $34 \%$ em relação à testemunha absoluta, sugerindo que o mesmo atua como promotor de crescimento (Tabela 3). Na presença de S. sclerotiorum os isolados UFSMT15.1, TC1.15, CP21, CP22, SP13, SP23 e SP24 não apresentaram bons resultados. Tsahouridou e Thanassoulopoulos (2002) reforçam que o tamanho de plântulas inoculadas com Sclerotium rolfsii e tratadas com Trichoderma spp. foram maiores em todos os tratamentos utilizados e com maior matéria seca do que nos tratamentos controle.

Tabela 3. Crescimento da parte aérea (CPA), crescimento do sistema radicular (CSR), matéria seca da parte aérea (MSPA) e do sistema radicular (MSSR) e matéria seca total (MST) para plântulas de alface cv. Regina oriunda de sementes tratadas com Trichoderma spp. obtidos de diferentes origens, na ausência e presença de S. sclerotiorum. Santa Maria (RS), 2012.

\begin{tabular}{|c|c|c|c|c|c|c|c|c|c|c|}
\hline & \multicolumn{2}{|c|}{$\mathrm{CPA}(\mathrm{cm})$} & \multicolumn{2}{|c|}{$\mathrm{CSR}(\mathrm{cm})$} & \multicolumn{2}{|c|}{$\mathrm{MSPA}^{4}(\mathrm{~g})$} & \multicolumn{2}{|c|}{$\operatorname{MSSR}^{4}(\mathrm{~g})$} & \multicolumn{2}{|c|}{$\mathrm{MST}^{4}(\mathrm{~g})$} \\
\hline $\begin{array}{c}\text { Trichoderma } \\
\text { spp. }\end{array}$ & Cont. $^{1}$ & Infestado $^{2}$ & Cont. & Infestado & Cont. & Infestado & Cont. & Infestado & Cont. & Infestado \\
\hline Testemunha & $3,44 \mathrm{bA}^{3}$ & $3,70 \mathrm{aA}$ & $2,70 \mathrm{bB}$ & $4,68 \mathrm{aA}$ & $0,025 \mathrm{cA}$ & $0,072 \mathrm{aA}$ & $0,007 \mathrm{aA}$ & $0,017 \mathrm{cA}$ & $0,032 \mathrm{cA}$ & $0,089 \mathrm{bA}$ \\
\hline UFSMT15.1 & $3,04 \mathrm{bA}$ & $3,01 \mathrm{bA}$ & $235 \mathrm{bA}$ & $1,84 \mathrm{bA}$ & $0,025 \mathrm{cA}$ & $0,012 \mathrm{bA}$ & $0,007 \mathrm{aA}$ & $0,002 \mathrm{cA}$ & $0,032 \mathrm{cA}$ & $0,014 \mathrm{cA}$ \\
\hline UFSMT17 & $3,82 \mathrm{aA}$ & $3,70 \mathrm{aA}$ & $2,36 \mathrm{bB}$ & $4,39 \mathrm{aA}$ & $0,045 \mathrm{cB}$ & $0,102 \mathrm{aA}$ & $0,010 \mathrm{aB}$ & $0,067 \mathrm{aA}$ & $0,055 \mathrm{cB}$ & $0,169 \mathrm{aA}$ \\
\hline TC1.15 & $3,28 \mathrm{bA}$ & $2,96 \mathrm{bA}$ & $2,40 \mathrm{bA}$ & $2,01 \mathrm{bA}$ & $0,040 \mathrm{cA}$ & $0,020 \mathrm{bA}$ & $0,007 \mathrm{aA}$ & $0,002 \mathrm{cA}$ & $0,047 \mathrm{cA}$ & $0,022 \mathrm{cA}$ \\
\hline ETSR20 & $3,68 \mathrm{bA}$ & $3,95 \mathrm{aA}$ & $2,68 \mathrm{bB}$ & $4,85 \mathrm{aA}$ & $0,077 \mathrm{bA}$ & $0,085 \mathrm{aA}$ & $0,007 \mathrm{aA}$ & $0,020 \mathrm{cA}$ & $0,084 \mathrm{cA}$ & $0,097 \mathrm{bA}$ \\
\hline $\mathrm{CP} 11^{5}$ & $4,60 \mathrm{aA}$ & $3,70 \mathrm{aB}$ & $2,53 \mathrm{~A}$ & $2,51 \mathrm{bA}$ & $0,057 \mathrm{cA}$ & $0,092 \mathrm{aA}$ & $0,002 \mathrm{aA}$ & $0,010 \mathrm{cA}$ & $0,059 \mathrm{cA}$ & $0,104 \mathrm{bA}$ \\
\hline CP12 & $4,29 \mathrm{aA}$ & $3,68 \mathrm{aA}$ & 4,28aA & $2,97 \mathrm{bA}$ & $0,157 \mathrm{aA}$ & $0,037 \mathrm{bB}$ & $0,030 \mathrm{aA}$ & $0,002 \mathrm{cA}$ & $0,187 \mathrm{aA}$ & $0,038 \mathrm{cB}$ \\
\hline CP21 & $3,48 \mathrm{bA}$ & $3,08 \mathrm{bA}$ & $2,44 \mathrm{bA}$ & $2,54 \mathrm{bA}$ & $0,062 \mathrm{cA}$ & $0,027 \mathrm{bA}$ & $0,012 \mathrm{aA}$ & $0,005 \mathrm{cA}$ & $0,074 \mathrm{cA}$ & $0,032 \mathrm{cA}$ \\
\hline CP22 & $3,90 \mathrm{aA}$ & $3,15 \mathrm{bB}$ & $3,32 \mathrm{aA}$ & $2,40 \mathrm{bA}$ & $0,082 \mathrm{bA}$ & $0,027 \mathrm{bA}$ & $0,005 \mathrm{aA}$ & $0,007 \mathrm{cA}$ & $0,089 \mathrm{bA}$ & $0,034 \mathrm{cA}$ \\
\hline SP $13^{6}$ & $3,86 \mathrm{aA}$ & $3,20 \mathrm{bA}$ & $3,73 \mathrm{aA}$ & 4,13aA & $0,087 \mathrm{bA}$ & $0,140 \mathrm{aA}$ & $0,022 \mathrm{aA}$ & $0,032 \mathrm{bA}$ & $0,109 \mathrm{bA}$ & $0,172 \mathrm{aA}$ \\
\hline SP23 & $4,06 \mathrm{aA}$ & $3,03 \mathrm{bB}$ & $2,90 \mathrm{bA}$ & $3,69 \mathrm{aA}$ & $0,085 \mathrm{bA}$ & $0,090 \mathrm{aA}$ & $0,025 \mathrm{aA}$ & $0,045 \mathrm{bA}$ & $0,110 \mathrm{bA}$ & $0,135 \mathrm{bA}$ \\
\hline SP14 & $3,06 \mathrm{bA}$ & $3,76 \mathrm{aA}$ & $2,09 \mathrm{bB}$ & $3,72 \mathrm{aA}$ & $0,035 \mathrm{cA}$ & $0,062 \mathrm{aA}$ & $0,003 \mathrm{aA}$ & $0,017 \mathrm{cA}$ & $0,038 \mathrm{cA}$ & $0,079 \mathrm{bA}$ \\
\hline SP24 & $3,45 \mathrm{bA}$ & $3,31 \mathrm{bA}$ & $2,37 \mathrm{bB}$ & $3,91 \mathrm{aA}$ & $0,057 \mathrm{cA}$ & $0,077 \mathrm{aA}$ & $0,007 \mathrm{aA}$ & $0,010 \mathrm{cA}$ & $0,064 \mathrm{cA}$ & $0,087 \mathrm{bA}$ \\
\hline CV (\%) & & \multicolumn{2}{|c|}{29,38} & \multicolumn{2}{|c|}{2,93} & \multicolumn{2}{|c|}{1,55} & \multicolumn{2}{|c|}{3,64} \\
\hline
\end{tabular}

${ }^{1}$ Cont.: tratamentos controle, sem S. sclerotiorum; ${ }^{2}$ Infestado: substrato infestado com S. sclerotiorum; ${ }^{3}$ Médias seguidas pela mesma letra minúscula na coluna e maiúscula na linha não diferem estatisticamente, segundo o teste de Scott-Knott $(\mathrm{P} \leq 0,05)$; ${ }^{4}$ Análise estatística realizada com dados transformados em $\sqrt[2]{x+0,5}$;
ente de áreas sem histórico de mofo-branco. 
Para a variável crescimento do sistema radicular fora observado que as plântulas cultivadas em substrato infestado com $S$. sclerotiorum foram superiores à testemunha absoluta, o que pode ter permitido às plântulas desencadear uma resposta contra $o$ patógeno, forçando o crescimento das raízes em busca de nutrientes para fugir do ataque fúngico. Nas plântulas tratadas apenas com Trichoderma spp. os isolados CP12, CP22 e SP13 se destacaram, sugerindo que estes atuam como promotores de crescimento do sistema radicular, já que permitiram ganhos de até $1,58 \mathrm{~cm}$ quando comparados às médias da testemunha absoluta.

Nas plântulas tratadas com o biocontrolador na ausência do patógeno verificou-se que UFSMT17, ETSR20, SP14 e SP24 tiveram valores para o sistema radicular estatisticamente iguais à testemunha absoluta, porém menores do que os seus correspondentes cultivados em substrato infestado com S. sclerotiorum, dando indícios que os referidos isolados agiram mais ativamente na presença do que na ausência do patógeno no substrato. Conforme sugerido por Pinto et al. (2011), pode ser uma característica específica da alface cv. Regina, já que também relataram maiores resultados para plantas cultivadas na presença de fitopatógenos, sugerindo que essa cultivar, em especial, pode ter moderada resistência a infecções fúngicas.

Todos os isolados do grupo CP, UFSMT15.1 e TC1.15 foram estatisticamente inferiores à testemunha na presença de S. sclerotiorum. Em especial, os dois últimos repetiram-se como ineficientes controladores do patógeno, assim como no crescimento da parte aérea. Segundo Mastouri et al. (2010), Trichoderma spp. são favorecidos pela presença de raízes, as quais colonizam facilmente, e aqueles que colonizam melhor a rizosfera podem ser adicionadas ao solo ou em sementes por qualquer método.

A promoção de crescimento desempenhada por Trichoderma spp. é confirmada pelos resultados obtidos para o peso de matéria seca da parte aérea em plantas cultivadas na ausência do patógeno, com destaque para CP12, com ganhos significativos em relação à testemunha absoluta, seguido de ETSR20, CP22, SP13 e SP23. Assim como Pinto et al. (2011) relatam que plantas de alface não inoculadas $\operatorname{com} S$. sclerotiorum apresentaram menores médias de matéria seca da parte aérea do que as inoculadas verificou -se também que a testemunha inoculada apenas com S. sclerotiorum obteve melhor média.

Para os dados de matéria seca do sistema radicular, na ausência do patógeno, os isolados de Trichoderma spp. não mostraram diferenças significativas em relação à testemunha absoluta, porém UFSMT17 foi estatisticamente menor do que o seu correspondente na presença de $S$. sclerotiorum. Na presença do patógeno, o mesmo isolado UFSMT17 foi o melhor, seguido por SP13 e SP23, com os demais igualando-se estatisticamente à testemunha. Em solo infestado por Pythium spp. ocorreu redução da maté- ria seca do sistema radicular em mudas de tomate, enquanto em sementes tratadas com $T$. harzianum as plântulas tiveram aumento de $46 \%$ quando comparadas à testemunha absoluta (MASTOURI et al., 2010).

Confirmando o potencial de biocontrole exercido pelos isolados de Trichoderma spp., CP12 obteve maior média para a matéria seca total em plântulas de alface cultivadas apenas com o biocontrolador, enquanto em substrato infestado com $S$. sclerotiorum os isolados UFSMT17 e SP13 foram os melhores. Os isolados UFSMT15.1, TC1.15, CP21 e CP22 apresentaram resultados insatisfatórios, sendo estatisticamente menores do que a testemunha infestada com o patógeno, sugerindo que os mesmos não são bons controladores de damping-off causado por S. sclerotiorum em plântulas de alface.

\section{CONCLUSÕES}

Dos oito isolados nativos de Trichoderma identificados dois pertencem a espécies $T$. koningiopsis e seis a T. asperellum. Todos os isolados de Trichoderma spp. utilizados foram eficazes na redução do crescimento micelial de $S$. sclerotiorum em meio de cultura, independente de sua origem.

Os isolados utilizados foram eficientes no controle de $S$. sclerotiorum, proporcionando maiores porcentagens de sobrevivência de plântulas de alface microbiolizadas, além de promoverem ganhos de matéria seca da parte aérea. No entanto, os isolados armazenados apresentaram redução na viabilidade tanto in vitro quanto in vivo, devendo-se optar, sempre que possível, por isolados nativos oriundos de áreas onde foi constatada a presença da doença em questão.

\section{REFERÊNCIAS}

ABDULLAH, M.T.; ALI, N. Y.; SULEMAN, P. Biological control of Sclerotinia sclerotiorum (Lib.) de Bary with Trichoderma harzianum and Bacillus amyloliquefaciens. Crop Protection, Oxford, v. 27, n. 10, p. 1354-1359, 2008.

ÁVILA, Z. R. et al. Seleção de isolados de Trichoderma spp. antagônicos a Sclerotium rolfsii e Sclerotinia sclerotiorum. Brasília: Embrapa Recursos Genéticos, 2005, 30p. (Boletim de Pesquisa e Desenvolvimento, 117).

BARAKAT, R. M.; AL-MAHAREED, F.; ALMASRI, M. I. Biological control of Sclerotium rolfsii by using indigenous Trichoderma spp. isolates from Palestine. Hebron University Research Journal, Hebron, v. 2, n. 2, p. 27-47, 2006. 
BELL, D. K.; WELLS, H. D.; MARKHAM, C. R. In vitro antagonism of Trichoderma species against six fungal plant pathogens. Phytopathology, Saint Paul, v. 72, n. 4, p. 379-382, 1982.

BRASIL. Ministério da Agricultura e Reforma Agrária. Regras para análise de sementes. Brasília: SNDA/DNDV/CLAV, 2009.

BRITO, J. P. C. et al. Peptaibols from Trichoderma asperellum TR356 strain isolated from Brasilian soil. Springer Plus, Heidelberg, v. 3, n. 1, p. 600-610, 2014.

BRITO, F. S.; MILLER, P. R. M.; STADNIK, M. Presença de Trichoderma spp. em composto e suas características para o controle de fitopatógenos. Revista Brasileira de Agroecologia, Porto Alegre, v. 5, n. 1, p. 43-53, 2010.

CLARKSON, J. P. et al. A model for Sclerotinia sclerotiorum infection and disease developmnet in lettuce, based on the effects of temperature, relative humidity and ascospore density. Plos One, Cambridge, v. 4, n. 9, p. 1-12, 2014.

DENNIS, C.; WEBSTER, J. Antagonistc properties of species groups of Trichoderma III. Hyphal Interactions. Transactions of the British Mycological Society, London, v. 57, n. 3, p. 363-369, 1971.

DRUZHININA, I. S. et al. Trichoderma: the genomics of opportunistic success. Nature Review Microbiology, v. 9, n. 10, p. 749-759, 2011.

ETHUR, L. Z. Dinâmica populacional e ação de Trichoderma no controle de fusariose em mudas de tomateiro e pepineiro. 2006. 154 f. Tese (Doutorado em Agronomia: Área de Concentração Fitopatologia) - Universidade Federal de Santa Maria, Santa Maria, 2006.

FERREIRA, D. F. Sisvar: a computer statistical analysis system. Ciência e Agrotecnologia, Lavras, v. 35, n. 6, p. 1039-1042, 2011.

GARCÍA-NÚÑEZ, H. G. Isolation of native strains of Trichoderma spp. from horticultural soils of the Valley of Toluca, for potential biocontrol of Sclerotinia. Tropical and Subtropical Agroecosystems, Valencia, v. 15, n. 2, p.357-365, 2012.

GHINI, R.; KIMATI, H. Método de isca para obtenção de isolados de Trichoderma antagônicos a Botrytis cinerea. Jaguariúna: Embrapa-CNPDA, 1989. 13p. (Boletim de Pesquisa, 3).

HOYOS-CARVAJAL, L.; ORDUZ, S.; BISSETT, J. Genetic and metabolic biodiversity of Trichoderma from Colombia and adjacent neotropic regions. Fun- gal Genetics and Biology, Orlando, v. 46, n. 6, p. 615-631, 2009.

INBAR, J.; MENENDEZ, A.; CHET, I. Hyphal interaction between Trichoderma harzianum and Sclerotinia sclerotiorum and its role in biological control. Soil Biology and Biochemistry, Missouri, v. 28, n. 6, p. 757-763, 1996.

$\mathrm{KIN}$, H. et al. Identification and characterization of Sclerotinia sclerotiorum NADPH oxidases. Applied and Environmental Microbiology, Washington, v. 77, n. 21, p. 7721-7729, 2011.

LILLY, G.V.; BARNETT, H. L. Physiology of the fungi. New York: McGraw-Hill Book, 1951. 464 p.

LOPES, F. A. C. et al. Biochemical and metabolic profiles of Trichoderma strains isolated from common bean crops in the Brazilian Cerrado, and potential antagonism against Sclerotinia sclerotiorum. Fungal Biology, Oxford, v. 116, n. 7, p. 815-824, 2012.

LOUZADA, G. A. S. et al. Potencial antagônico de Trichoderma spp. originários de diferentes agroecossistemas contra Sclerotinia sclerotiorum e Fusarium solani. Biota Neotrópica, Campinas, v. 9, n. 3, p. 145-149, 2009.

MASTOURI, F.; BJÖRMAN, T.; HARMAN, G. E. Seed treatment with Trichoderma harzianum alleviates biotic, abiotic and physiological stresses in germinating seeds and seedlings. Phytopathology, Saint Paul, v. 100, n. 11, p. 1213-1221, 2010.

PINTO, Z. V. et al. Podridão de raízes causadas por Pythium aphanidermatum em cultivares de alface produzidas em sistema hidropônico. Summa Phytopathologica, Botucatu, v. 37, n. 4, p. 180-186, 2011.

QUALHATO, T. F. et al. Mycoparasitism studies of Trichoderma species against three phytopathogenic fungi: evaluation of antagonism and hydrolytic enzyme production. Biotechnology Letters, v. 35, n. 9, p. 1461-168, 2013.

RODRIGUES, J. Trichoderma spp. associado a níveis de adubação NPK no patossistema Sclerotinia sclerotiorum-feijoeiro. 2010. 85f. Dissertação (Mestrado em Agronomia: Área de Concentração Fitopatologia) - Universidade Federal de Santa Maria, Santa Maria, 2010.

SALA, F. C.; COSTA, C. P. Retrospectiva e tendência da alfacicultura brasileira. Horticultura Brasileira, Brasília, v. 30, n. 2, p. 187-194, 2012.

TSAHOURIDOU, P. C.; THANASSOULOPOULOS, C. C. Proliferation of Trichoderma koningii in 
the tomato rhizosphere and the suppression of damping-off by Sclerotium rolfsii. Soil Biology and Bio-

chemistry, Missouri, v. 34, n. 6, p. 767-776, 2002. 